\title{
Length-weight relationship and condition factor of Sphyraena afra from the coastal waters of Lagos State
}

\author{
Caroline Ireti Ayo-Olalusi, Adedolapo Abeke Ayoade
}

Received - 23 January 2016/Accepted - 16 January 2019. Published online: 31 March 2019; Inland Fisheries Institute in Olsztyn, Poland Citation: Ayo-Olalusi C.I., Ayoade A.A. 2019 - Length-weight relationship and condition factor of Sphyraena afra from the coastal waters of Lagos State - Fish. Aquat. Life 27: 27-31.

\begin{abstract}
The length-weight relationship and condition factor of Sphyraena afra from the Lagos coast (LC) and the Lagos lagoon complex (LLC) in the coastal waters of Lagos State were studied for a period of two years. Parameters a and b of the length-weight relationship were estimated using the equation $\mathrm{W}=\mathrm{a} \times \mathrm{TL}^{\mathrm{b}}$, while the condition factor was calculated with the equation $\mathrm{K}=100 \times \mathrm{BW} \times \mathrm{TL}^{-3}$. The relationships of fish condition factor and body length, sex, and seasons in Lagos coastal waters were determined. The species exhibited negative allometric growth $(\mathrm{b}<3$, $\mathrm{P}<0.05)$ for males, females, and combined sexes with the length exponent (b) ranging from 2.72 to 2.85. Correlation coefficient $r$ ranged from 0.89 to 0.98 . The allometric growth values obtained in LC and LLC from the length-weight relationship indicated that the fish species exhibited increases in length rather than in weight. The overall mean condition factors (K) for $S$. afra from the LC and the LLC were $0.97 \pm 0.11$ and $1.17 \pm 0.12$, respectively. The mean condition factors of females were higher than those for males at most of the sampling stations, and $S$. afra was observed to be in better condition during the dry season.
\end{abstract}

Keywords: Sphyraena afra, condition factor, length-weight relationship, correlation coefficient

C.I. Ayo-Olalusi [ $\left.\Xi^{\circ}\right]$

Department of Biotechnology,

Nigerian Institute for Oceanography and Marine Research

3 Wilmot Street, Victoria Island, Lagos, Nigeria

e-mail: iretioluwaa@yahoo.com; ireti.ayoolalusi@yahoo.com

A.A. Ayoade

Department of Zoology, University of Ibadan, Ibadan, Nigeria

\section{Introduction}

Barracudas are commercial species of the Sphyraenidae family that occur in tropical and subtropical oceans. The Sphyraenidae includes only one genus, Sphyraena, with 21 species (Nelson 2006). Four species of the genus Sphyraena were collected from the coastal waters of Lagos State and were identified using FAO guides as Sphyraena afra Peters, Sphyraena guachancho Cuvier, Sphyraena barracuda (Edwards), and Sphyraena sphyraena (L.) (Carpenter and De Angelis 2016). S. afra is the most abundant and commonly seen of these species in both estuaries and marine waters. The fish commands a high market value, is in high consumer demand, and is a candidate for marine culture. Establishing length-weight relationships (LWRs) is a basic, regular task in fisheries research. Length-weight relationships provide useful information for fishery management and for both basic and applied purposes (Pitcher and Hart 1982). The condition factor expresses the condition of a fish, such as the degree of well-being, relative robustness, and plumpness or fatness in numerical terms, and it is based on the hypothesis that heavier fish of a given length are in better condition (Bagenal and Tesch 1978). Length-weight relationships of marine fish resources in Nigeria are limited, and the LWR for $S$. 


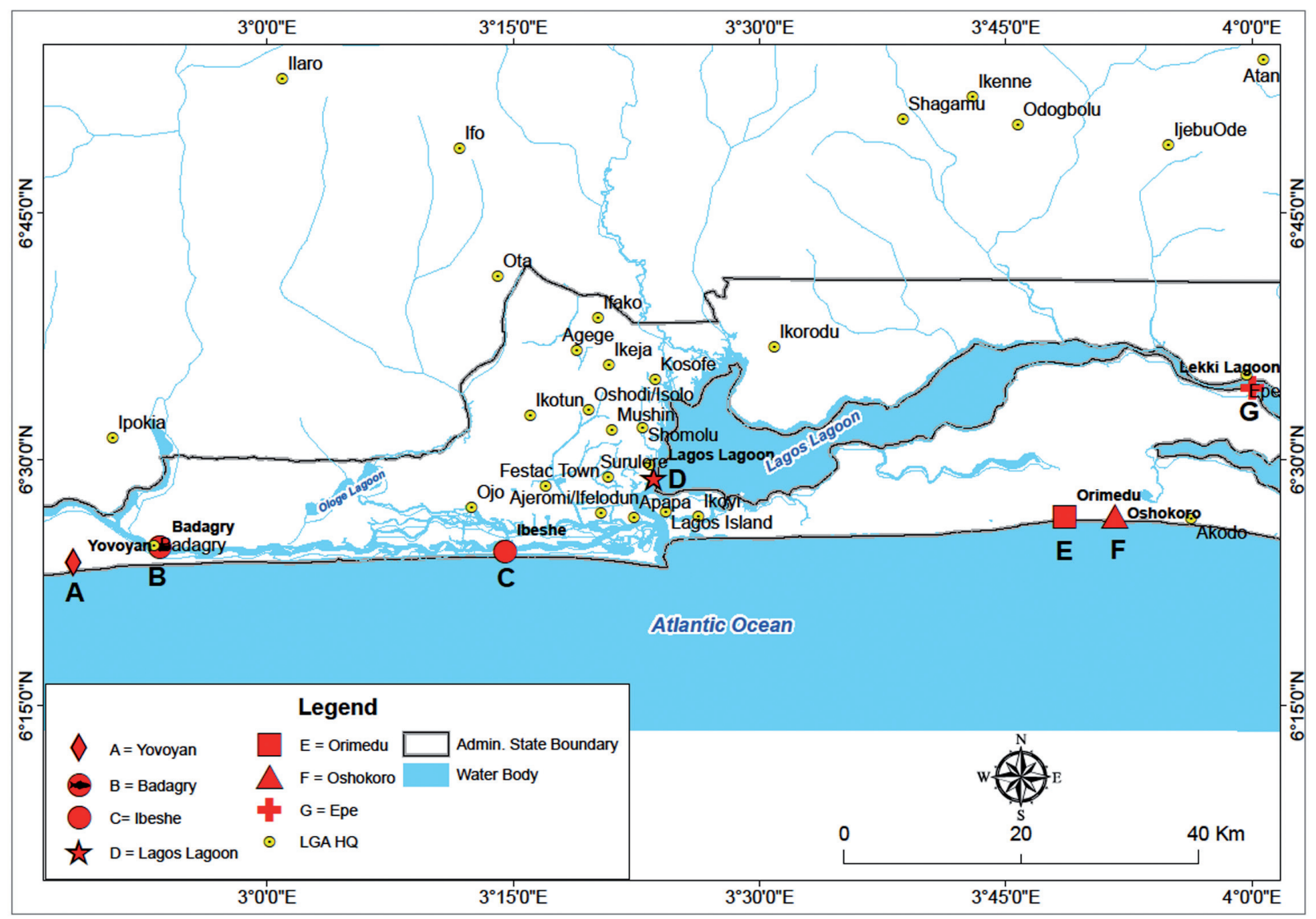

Figure 1. Map of coastal waters of Lagos State showing sampling stations.

afra was not available in Fish Base (Froese and Pauly 2019). The aim of this article is to provide information on the LWRs of $S$. afra that will foster the development of successful management programs in the wild and in culture in the coastal waters of Lagos State.

\section{Material and methods}

The study area was in the coastal waters of Lagos State, and seven stations were selected; three from the Lagos lagoon complex (LLC; Lagos, Lekki, and Badagry lagoons) and four from off the Lagos coast (LC; Yovoyan, Ibeshe, Oshoroko, and Orimedu). The stations were selected to cover the west by the Republic of Benin and the south stretching for $200 \mathrm{~km}$ along the coast of the Atlantic Ocean. The study area was located between the longitudes of $2^{\circ} 45^{\prime}$ and $3^{\circ} 60^{\prime}$ and the latitudes of $6^{\circ} 20^{\prime}$ and $6^{\circ} 34^{\prime}$ (Fig. 1 ). The climate is typical of rainforest/tropical coastal waters with a prolonged wet season (April to October) and a short dry season (November to March). Monthly sampling was carried out from August 2009 to July 2011. Water temperature, dissolved oxygen, salinity, and water transparency were measured in-situ with a mercury-in-glass thermometer and validated with a Jenway DO meter, a hand refractometer (Biomarine, Aquafauna model), and a Secchi disc (Model 9071), respectively. Specimens were collected at landing sites of the seven stations from local fishermen who used combinations of fishing gears that included trawl nets, purse seines, gill nets, trammel nets, and longlines. The species were 
Table 1

Results of the physicochemical parameters of the coastal waters of Lagos State

\begin{tabular}{lllll}
\hline \hline & \multicolumn{2}{l}{ Lagos coast } & & \multicolumn{2}{l}{ Lagos lagoon complex } \\
\cline { 2 - 5 } Parameters & Rainy season & Dry season & Rainy season & Dry season \\
\hline \hline Temperature $\left({ }^{\circ} \mathrm{C}\right)$ & $27.5 \pm 0.12$ & $30.5 \pm 0.11$ & $27.5 \pm 0.20$ & $30.7 \pm 0.08$ \\
Salinity $(\%)$ & $27.1 \pm 0.06$ & $33.2 \pm 0.02$ & $1.2 \pm 0.11$ & $7.2 \pm 0.03$ \\
Water transparency $(\mathrm{m})$ & $0.25 \pm 0.02$ & $0.51 \pm 0.12$ & $0.17 \pm 0.04$ & $0.39 \pm 0.01$ \\
Dissolved oxygen $\left(\mathrm{mg} \mathrm{O}_{2} \mathrm{dm}^{-3}\right)$ & $5.6 \pm 0.08$ & $7.5 \pm 0.13$ & $5.5 \pm 0.11$ & $7.3 \pm 0.18$ \\
\hline \hline
\end{tabular}

identified with the FAO guide. The total length (TL) and body weight (BW) of fish specimens were measured to the nearest $0.1 \mathrm{~cm}$ with a meter rule and to the nearest $0.01 \mathrm{~g}$ with a digital scale, respectively. LWRs were calculated with linear regressions of log-transformed data of the equation $\mathrm{BW}=\mathrm{a} \times \mathrm{TL}^{\mathrm{b}}$, where $\mathrm{BW}=$ weight $(\mathrm{g})$, TL = total length $(\mathrm{cm})$, and $\mathrm{a}$ is the intercept and $\mathrm{b}$ is the allometric coefficient (Roff 1986). Fulton's condition factor (K) to determine fish wellbeing (Ricker 1975) was calculated using the following equation: $\mathrm{K}=100 \times \mathrm{BW} \times \mathrm{TL}^{-3}$. The data collected were analyzed using descriptive statistics (means and standard deviation). All the analysis was performed using IBM SPSS 20.0 at significance levels of $\mathrm{P}=0.05$ and $\mathrm{P}<0.001$. Analysis of covariance was used to compare the length-weight relationship between the sexes, condition factors between the sexes, seasons, and length. The Chi square $\left(\mathrm{X}^{2}\right)$ test was used to determine if a population contained equal proportions of males and females. The t-test was used to determine the level of significance of the parameters in the two water bodies.

\section{Results}

The results of the physicochemical parameters are shown on Table 1 . The surface water temperature mean values ranged from $27.5 \pm 0.12$ to $30.7 \pm 0.08^{\circ} \mathrm{C}$, mean salinity values ranged from 1.2 \pm 0.11 to $7.2 \pm 0.03 \%$ in $\mathrm{LC}$ and $27.1 \pm 0.06$ to 33.2 \pm 0.02 in LLC. LC had higher salinity gradients than LLC (Table 1). Water transparency ranged from 0.17 $\pm 0.04 \mathrm{~m}$ to $0.51 \pm 0.12 \mathrm{~m}$, while the dissolved oxygen mean values ranged from $5.5 \pm 0.11$ to $7.5 \pm$ $0.13 \mathrm{mg} \mathrm{L}^{-1}$ (Table 1).

A total of 2,354 specimens (LLC: $\mathrm{n}=638$; LC: $\mathrm{n}$ $=1,716)$ were examined. Descriptive statistics and estimated parameters of length-weight relationships for S. afra are shown in Table 2, while Table 3 presents the summary of the length-weight equation of $S$. afra from the coastal waters of Lagos State. The b values ranged from 2.75 to 2.85 in LLC and from 2.72 to 2.75 in LC. The coefficient of determination ranged from 0.94 to 0.95 and 0.89 to 0.93 in LLC and LC, respectively.

\section{Discussion}

A characteristic of the length-weight relationship in fishes and invertebrates is that the value of exponent $\mathrm{b}$ is 3 when growth is isometric (without changing shape), while $b>3$ is positive allometric growth and $\mathrm{b}<3$ is negative allometric growth. Statistical analysis of the length-weight data showed that $S$. afra males, females, and the sexes combined exhibited negative allometric growth in the coastal waters of Lagos State since the value of $b$ (the exponential) of the regression equations representing their length-weight relationships was less than 3. The allometric growth values obtained at all the stations from the length-weight relationships indicated that the fish species exhibited increased length rather than weight. These showed that even though there were corresponding increases in weight and length, 
Table 2

Descriptive statistics and estimated parameters of the length-weight relationship of S. afra from the coastal waters of Lagos State

\begin{tabular}{|c|c|c|c|c|c|c|c|c|c|c|}
\hline \multirow[b]{2}{*}{ Location } & \multirow[b]{2}{*}{$\mathrm{N}$} & \multirow{2}{*}{$\frac{\mathrm{TL}(\mathrm{cm})}{\operatorname{Min}-\operatorname{Max}}$} & \multirow{2}{*}{$\begin{array}{l}\text { BW }(g) \\
\text { Min-Max }\end{array}$} & \multirow{2}{*}{$\begin{array}{l}\begin{array}{l}\text { Fulton } \\
\text { condition factor }\end{array} \\
\text { Min-Max }\end{array}$} & \multirow{2}{*}{$\begin{array}{l}\begin{array}{l}\text { Mean Fulton } \\
\text { condition factor }\end{array} \\
\text { Mean } \pm \text { SD }\end{array}$} & \multicolumn{5}{|c|}{ Regression parameters } \\
\hline & & & & & & a & $\mathrm{b}$ & $95 \% \mathrm{Cl}$ of $\mathrm{b}$ & SE (b) & $r^{2}$ \\
\hline \multicolumn{11}{|c|}{ Lagos lagoon complex } \\
\hline Males & 296 & $18.9-183.3$ & $28.5-25000$ & $0.76-1.15$ & $1.13 \pm 0.24$ & 0.0088 & 2.75 & $2,71-2.790$ & 0.076 & 0.94 \\
\hline Females & 342 & $18.0-153.2$ & $27.6-15300$ & $0.95-1.21$ & $1.19 \pm 0.18$ & 0.0092 & 2.85 & $2,743-2.970$ & 0.059 & 0.95 \\
\hline Sum & 638 & 18.0-183.3 & $27.6-25000$ & $0.76-1.21$ & $1.17 \pm 0.12$ & 0.009 & 2.80 & $2,721-2.890$ & 0.068 & 0.95 \\
\hline \multicolumn{11}{|c|}{ Lagos coast } \\
\hline Males & 820 & $17.6-116.9$ & $27.2-6305$ & $0.89-1.18$ & $0.96 \pm 0.13$ & 0.01125 & 2.72 & $2,669-2.785$ & 0.092 & 0.93 \\
\hline Females & 896 & $18.4-154.4$ & $27.3-15300$ & $0.93-1.21$ & $0.98 \pm 0.24$ & 0.01144 & 2.75 & $2,761-2.828$ & 0.112 & 0.89 \\
\hline Sum & 1716 & $17.6-154.4$ & $27.3-15300$ & $0.89-1.21$ & $0.97 \pm 0.11$ & 0.01135 & 2.73 & $2,720-2.802$ & 0.087 & 0.91 \\
\hline
\end{tabular}

$\mathrm{N}$ - sample size, TL - total length $(\mathrm{cm}) \mathrm{m}$ BW - body weight $(\mathrm{g})$, a - intercept, b - slope, allometric growth coefficient, CL confidence limit; SE (b) - standard error of slope $b ; \mathrm{r}^{2}$ - coefficient of correlation

Table 3

Summary of the length-weight equation of $S$. afra from coastal waters of Lagos State

\begin{tabular}{llll}
\hline \hline Location & $\mathrm{N}$ & Equation $(\mathrm{BW}=\mathrm{a} \mathrm{TL})$ & $\mathrm{r}^{2}$ \\
\hline \hline Lagos lagoon complex & 638 & $\mathrm{BW}=0.0090 \mathrm{TL}^{2.80}$ & 0.91 \\
Lagos coast & 1716 & $\mathrm{BW}=0.01135 \mathrm{TL}^{2.73}$ & 0.95 \\
\hline \hline
\end{tabular}

$\mathrm{N}$ - sample size, BW - fish body weight, TL - total length, $\mathrm{r}^{2}$ coefficient of correlation

at certain stages of fish growth, increases in weight ceased to be directly proportional to increases in length as revealed in some fish species. The $b$ value range determined of 2.72-2.85 for $S$. afra in this study fell within the expected range of 2.7-3.4 (Froese 2006) and that of 2.5-3.49 reported for great barracuda, S. barracuda (Froese and Pauly 2019). Jaiswar et al. 2004 reported a b value range of 2.72-2.73 for Sphyraena obtusata Cuvier in Bombay waters of the west coast of India, while a $b$ value range of 2.84-2.89 was reported for the same species from the Jaffna Lagoon in Sri Lanka (Sivashanthini et al. 2009). Hosseini et al. (2009) also reported a b value range of 2.77-2.87 for Sphyraena jello Cuvier from the Persian Gulf. Some investigators reported that slight differences in $\mathrm{b}$ values could have been due to the variations in environmental or ecological conditions of different habitats or to the variation in the physiology of the animals or both (Bhattacharya and Acharya 1984, Jaiswar and Kulkarni 2002).
Variations in the coefficient of condition of fish primarily reflect the state of sexual maturity and the degree of nourishment. Wootton (1990) reported fish species with high $\mathrm{K}$ values are heavy for their length, while those with low K values are light for their length. The condition factor values of $S$. afra females were higher than those of males. This could have stemmed from differences in gonad development. The highest $\mathrm{K}$ values are attained in fish that are fully mature and have the highest reproductive potential (Agboola et al. 2008). The overall mean condition factor (K) for $S$. afra of $0.97 \pm 0.12$ and $1.17 \pm 0.11$ obtained off the LC and the LLC, respectively, indicated better condition in LC than in LLC, and these values varied slightly with the results of other studies: Kumolu-Johnson and Ndimele (2010) reported a K value of 1.92 for $S$. afra in the Ologe Lagoon, and Philips (2014) obtained a $\mathrm{K}$ value of 0.651 (calculated by gutted weight) for Merluccius merluccius (L.) from Egyptian Mediterranean waters. S. afra was observed to be in better condition during the dry season.

In conclusion, the LWR of $S$. afra revealed negative allometric growth in the two water bodies. The $\mathrm{K}$ value suggested that the condition of the coastal waters of Lagos State is favorable for the species. S. afra can survive off of the LC and LLC and in good condition despite the differences in the salinity gradient of the two environments. The present study provides 
the first records of LWRs of this species, which will enhance its effective management and conservation. High dissolved oxygen content indicated that the coastal water of Lagos State can successfully support aquatic life including fish.

Acknowledgments. The authors would like to acknowledge the staff of Biotechnology Department of the Nigerian Institute for Oceanography and Marine Research (NIOMR), Victoria Island, Lagos, Nigeria, for their technical assistance throughout the course of the study.

Author contributions. A.C.I. designed the research and statistically analysed the data; A.C.I. and A.A.A. performed the research and wrote the paper.

\section{References}

Agboola J.I., Anetekhai M.A., Denloye A.A. 2008 - Aspects of the ecology and fishes of Badagry creek (Nigeria) - J. Fish. Aquat. Sci. 3: 184-194.

Bagenal T.B., Tesh F.W. 1978 - Age and growth - In: Methods for Assessment of Fish Production in Freshwater (Ed.) T.B. Bagenal, Blackwell Scientific Publications Oxford: 81-89.

Bhattacharya D., Acharya P. 1984 - A note on length-weight relationship of Polynemus heptadactylus - Geobios New Reports 3: 62-64.

Carpenter K.E., De Angelis N. 2016 - The living marine resources of the eastern central Atlantic. Vol. 4: Bony fishes parts and sea turtles. FAO Species Identification Guide for Fishery Purposes, Rome, FAO: 2343-3124.

Froese R. 2006 - Cube law, condition factor and weight-length relationships: history, meta-analysis and recommendations - J. Appl. Ichthyol. 22: 241-253.
Froese R., Pauly D. 2019 - FishBase - World Wide Web electronic publication, www.fishbase.org, version (02/2019).

Hosseini S.A., Jamili S., Vallinassab T., Vosoghi G., Fatemi S.M.R. 2009 - Feeding and Spawning of Sphyraena jello in the north west of Persian Gulf - J. Fish. Aquat. Sci. 4: 57-62.

Jaiswar A.K., Kulkarni B.G. 2002 - Length-weight relationship of intertidal molluscs from Mumbai, India - J. Indian Fish. Assoc. 29: 55-63.

Jaiswar A.K., Parida P.K., Chakraborty S.K., Palaniswamy R. 2004 - Morphometry and Length-weight relationship of obtuse barracuda Sphyraena obstusata (Cuvier) (Teleostomi/Actinopterygii/ Sphyraenidae) from Bombay waters, west coast of India - Indian J. Mar. Sci. 33: 307-309.

Kumolu-Johnson C.A., Ndimele P.E. 2010 - Length-weight relationships and condition factors of twenty-one fish species in Ologe Lagoon, Lagos, Nigeria - Asian J. Agricult. Sci. 2: 174-179.

Nelson J.S. 2006 - Fishes of the world. $4^{\text {th }}$ Edition - John Wiley and Sons, New York, p. 601.

Philips A.E. 2014 - Comparison of some biological aspects between the two sexes of the European hake Merluccius merluccius from the Egyptian Mediterranean waters Egypt. J. Aquat. Res. 40: 309-315

Pitcher T.J., Hart P.J. 1982 - Fisheries ecology - Chapman and Hall, London, 414 p.

Ricker W.E. 1975 - Computation and interpretation of biological statistics of fish population - Bull. Fish. Res. Board Can. 191: 1-382.

Roff D.A. 1986 - Predicting body size with life history models - BioScience 36: 316-323.

Sivashanthini K., Gayathri G., Gajapathy K. 2009 Length-weight relationship of Sphyraena obtusata Cuvier, 1829 (Pisces: Perciformes) from the Jaffna Lagoon, Sri Lanka - J. Fish. Aquat. Sci. 4: 111-116.

Wootton R.J. 1990 - Ecology of Teleost Fishes. Chapman \& Hall, London, 404 p. 